\title{
Integrating technology with literacy: using teacher-guided collaborative online learning to encourage critical thinking
}

\author{
Alyson Simpson* \\ Faculty of Education and Social Work, University of Sydney, Sydney, Australia
}

(Received 7 August 2009; final version received 19 April 2010)

\begin{abstract}
This paper reports on classroom-based research that was designed to monitor the integration of information and communication technology (ICT) in a teacherguided collaborative online learning context to encourage students' critical response to literary texts. The study investigates the premise that an ICT project where children read books and then use email communication to exchange responses with other learners will support critical thinking. Videos of classroom observations, journals and rap sheets were analysed for individual students' levels of critical awareness. Improvements in critical thinking were measured using linguistic analysis. Teachers and students were also interviewed for attitudes to technology use related to learning. Although there were gains in critical thinking, there was little student engagement with technology. The discussion problematises the integration of technology in the classroom through a repositioning of collaboration in a blended learning context known as book raps.
\end{abstract}

Keywords: blended learning; critical thinking; collaboration; e-learning; linguistic analysis; reading

\section{Introduction}

This paper is an evaluative study of technology use in learning and teaching in a primary school setting in Australia. It demonstrates the link between research and good practice that is created when practitioners and researchers join to investigate how technology can meet strategic learning goals. The impact of information and communication technology (ICT) on student learning is critiqued through a close analysis of a collaborative online learning community (COLC) that supports the authentic integration of technology with literacy.

COLCs are becoming common in schools as the power of online learning to engage students in learning tasks is realised, and as the use of networked computers in education increases (Department of Education Science and Training 2001; Lankshear et al. 1997). This study demonstrates the use of entry-level web technologies such as email to engage students and teachers during their first experience of a COLC project. The paper investigates changes in students' critical awareness, and teachers' perception of ICT use. Literacy outcomes are tracked via links to the pedagogic design of the online communication and considered finally through the lens of teacher reflection, to make connections between learning and ICT use.

*Email: alyson.simpson@sydney.edu.au 


\section{Background}

The past 10 years have seen massive investment in educational ICT infrastructure. Yet education systems all over the world face the challenge of designing activities that encourage collaborative learning (Downing et al. 2007; Salmon 2000; Ellis et al. 2007). Studies of agency in the use of ICT are critical to this debate for, as Bell states: "learning technology research can fall into the trap of focusing on the technology that is offered rather than what people do with or without it" (Bell 2009, 73). Therefore research is needed into contexts where technology is a means of meeting strategic goals for teachers and their students.

Previous research into the incorporation of ICT into primary school classrooms has investigated the professional development of teachers (Simpson and Ollila 2004). In order to document the impact of ICT technology on teaching practice, a study by Schibeci et al. (2008) proposed a pedagogic framework. Their framework proposes four stages of development towards critical pedagogy: (1) Where's the ON button?, (2) Black Line mastery, (3) Routine student use, and (4) What's in the curriculum? (Schibeci et al. 2008, 318). Other studies have reported on the adoption of ICT in relation to teacher values and beliefs as reviewed by Webb and Cox (2004). However, it is well known that additional factors other than teacher attitude influence the successful use of ICT in the classroom. There are operational, cultural and critical dimensions in any learning context (Durrant and Green 2000, 89). Although operational issues such as computer access can shape what it is possible to achieve, the book rap study focuses more on the teacher's role in a COLC from the two other dimensions cultural and critical. Teachers' values and beliefs about the ICT used to improve student's critical thinking will be read as part of the local classroom culture. Teachers' shift in critical awareness of the ICT adopted in their literacy programme will be read from a critical perspective.

The role of the teacher in COLCs has been a complementary focus in further research into ICT (Turvey 2006). Research shows that elements such as teacher participation contribute to students' learning online (Dillenbourg and Traum 2006). For example, a typical COLC would be organised so a teacher designs, maintains and creates learning interactions online. The concept of teacher presence was originally developed to encapsulate the crucial impact that teachers' involvement can have on students in distance education (Anderson et al. 2001, 5). In contrast to Anderson et al.'s work, the COLC context of book raps operates within a blended learning environment where students interact with both an online moderator and a classroom teacher who guide, discipline, teach, and so forth. This pedagogic design difference changes the patterns of interaction that each 'teacher' has with their students. Although the book rap data show that more collaboration takes place in the classroom than online, the small proportion of collaboration that does take place online is vital to the learning exercise.

This paper enriches previous research by examining changes in teacher practice and the outcomes for primary school learners in a COLC context. Through analysis of cultural artefacts such as journal entries, face-to-face discussion, and picture books, which all contribute to the content of online postings, the study evaluates patterns of change in student activity and mental processes (Owen 2004, 30). It demonstrates students' capacity to work in environments that require simultaneous control of multiple literacies such as visual, textual and digital as they deal with web and print-based communication to develop critical thinking (Simpson and Walsh in press). 


\section{Book raps}

This study was designed to view the impact that a particular form of COLC, known in Australia as book raps, had on students in a primary school. Book raps are one example of interactive learning providing a specialist focus to encourage the love of children's literature and students' close reading of literary texts through moderated and teacher-guided online sharing of responses (Stubbs 1999). Their use is described in detail in a book about children's literature and technology by Unsworth et al., who state: "As a direct result of their interactive design, book raps have stimulated children's enthusiasm and enjoyment of books, bringing about more complex modes of communication and therefore more complex appreciation of texts" $(2005,40)$. In New South Wales, the Department of Education (DET) supports raps. ${ }^{1}$ To participate, individual schools nominate a particular rap by signing on to a discussion list via the moderated website. Before a rap commences, the books to be discussed, the rap points to scaffold discussion of the book and teachers' support notes are published on the education system web page. During the rap, the students read the nominated book and work through the rap points with teacher guidance. Teachers and students use the rap points and rap sheets (scaffolded work sheets) to focus their discussions and activities. After each rap point has been discussed, the students share responses with face-to-face peers and decide on a shared or individual message to be sent to the moderator. The moderated responses are posted on a general discussion list for others who belong to their community to read.

\section{Methodology}

The research took place in a medium-sized primary school, Inner West Public (IWP), located in Sydney, Australia. Since book raps have been listed on the DET website, uptake of this interactive learning opportunity has engaged many primary schools with group sizes varying from 20 to 200 schools/classes. For IWP it was their first introduction to book raps. The teachers were keen to find an authentic means of incorporating technology into their classrooms, and chose book raps as a teaching tool to enrich their usual guided reading practices. They agreed to collect data to monitor the effectiveness of the initiative.

Ethics permission was sought from parents, students and teachers to observe, record and collect data. Material from the DET rap website is available for public access but remains the property of the DET and is subject to their copyright control. Ethics permission for the overall study was also granted by DET.

Forty students from IWP took part in activities for a period of six weeks. Data were collected from the students of two composite Year Four/Five classes. The intervention was offered to all Year Five students whilst the Year Four students completed a different kind of literature study. The 40 students observed for the book rap research were arranged into six ability groups for the duration of the book rap. The teachers believed that levelled reading groups suited the learning needs of these children best, so, in order to minimise disruption to the classroom, the researcher did not tamper with these groupings.

The research was planned as a small-scale qualitative, interpretive research study to examine the impact of a new COLC on the literacy outcomes of a group of primary school students aged 9-10. The key research question in the study was: how does online collaborative learning support critical thinking? Improvements in critical 
thinking were measured using linguistic analysis informed by Halliday's functional theory of language (Halliday 1975; Martin 2000). This theory provides the study with a measure of the children's critical awareness through an examination of their language use. As the books used in the research study were the picture books shortlisted for the Children's Book Council Awards, ${ }^{2}$ the students were working towards critical literacy outcomes that depended on knowledge about the construction of meaning in text and images. When children talk about how authors and illustrators make them respond to the books by using language about language (meta-language), this is judged as a sign of their developing critical capacity (Christie 2002; Unsworth 2000). This theoretical approach underpins the analysis of the data so that when the children in the study wrote responses via email or in journals or rap sheets, any changes towards critical response could be measured linguistically.

The research was carried out in four phases as data became available (Table 1). The first phase was the collection of online instructions and teaching materials for analysis of interactive design elements created by the moderator. Second, videos of classroom observations, journals and rap sheets were analysed for individual students' initial levels of critical awareness. In the third phase, three focus students were chosen by the classroom teachers to represent the range of ability groupings they wanted

Table 1. Overview of phases.

\begin{tabular}{|c|c|c|}
\hline Phase & Context & Methods \\
\hline $\begin{array}{l}\text { 1. The moderator } \\
\text { prepares the site }\end{array}$ & $\begin{array}{l}\text { Book Week rap hosted on DET } \\
\text { website }\end{array}$ & $\begin{array}{l}\text { Rap points were collected from } \\
\text { website for analysis }\end{array}$ \\
\hline \multirow[t]{3}{*}{$\begin{array}{l}\text { 2. Face-to-face class } \\
\text { work }\end{array}$} & $\begin{array}{l}\text { Teachers prepare and support } \\
\text { students in rap work }\end{array}$ & $\begin{array}{l}\text { Videos of classroom interactions in } \\
\text { each ability group were analysed } \\
\text { for meta-language and students' } \\
\text { critical awareness }\end{array}$ \\
\hline & $\begin{array}{l}\text { Students read texts and discuss } \\
\text { rap points in class groups based } \\
\text { on one of four books }\end{array}$ & $\begin{array}{l}\text { Students' response journals and rap } \\
\text { sheets were analysed for shifts in } \\
\text { critical awareness }\end{array}$ \\
\hline & $\begin{array}{l}\text { Students write individual text } \\
\text { responses as journal entries, on } \\
\text { rap sheets }\end{array}$ & $\begin{array}{l}\text { Levels of awareness change were } \\
\text { identified in classroom-based } \\
\text { data }\end{array}$ \\
\hline \multirow[t]{4}{*}{ 3. Work online } & $\begin{array}{l}\text { IWP and students post responses } \\
\text { to rap list in form of emails and } \\
\text { read posts from other rap } \\
\text { groups in other schools (DS) }\end{array}$ & $\begin{array}{l}\text { Email rap postings were collected } \\
\text { from IWP and DS students }\end{array}$ \\
\hline & & $\begin{array}{l}\text { Targeted sampling of focus } \\
\text { students from IWP was made } \\
\text { from three ability-level groups }\end{array}$ \\
\hline & & $\begin{array}{l}\text { Patterns of critical awareness of } \\
\text { focus children across the six } \\
\text { weeks were analysed }\end{array}$ \\
\hline & & $\begin{array}{l}\text { All IWP postings were read for } \\
\text { general trends and DS postings } \\
\text { were read for sophisticated } \\
\text { examples of critical awareness }\end{array}$ \\
\hline $\begin{array}{l}\text { 4. During face-to- } \\
\text { face class work }\end{array}$ & $\begin{array}{l}\text { Students and teachers discussed } \\
\text { the impact of the book rap on } \\
\text { their learning with researchers }\end{array}$ & $\begin{array}{l}\text { Video interviews with teachers and } \\
\text { students were analysed for levels } \\
\text { of critical awareness and attitude } \\
\text { to technology use }\end{array}$ \\
\hline
\end{tabular}


tracked. These students became the target sample and their datasets were analysed in close detail. The findings from this analysis provided evidence of their individual changes over the whole book rap. The researcher and teachers recognised that the group of three could not provide definitive proof of changes for all. A larger study was needed to make that kind of claim, however; when read against the complete body of data, the results from the focus students could indicate where clusters of students' changing critical awareness would possibly group.

Email postings from students from different schools were also analysed in this phase to enable benchmark comparisons with IWP students in terms of levels of critical awareness gained by the end of the book rap. During the fourth phase, teachers and focus students were interviewed for attitudes to technology use related to learning during the book rap.

\section{Procedure}

In order to collect data that were a valid representation of improvements in critical thinking and the impact of technology across the book rap, three different forms of response activity materials were selected. The dataset included students' response journals, completed rap sheets and email postings. These materials were collected over six weeks as the rap ran and provide three different perspectives of the learning as it took place. The data were coded and analysed for patterns of grammar use that demonstrated capability with abstract thinking and knowledge of technical vocabulary about text and visual literacy as an additional marker of growing critical awareness. Linguistic analysis was completed on sets of student texts for evidence of abstract thinking on a cline from description to personal opinion and finally critical awareness. This cline was based on concepts from Bloom's taxonomy of educational objectives (Bloom et al. 1956) to create coding categories for levels of understanding. This information was used to create a simple benchmark measure of literacy outcomes at the beginning of the rap (see Figure 1). Four levels of coding - comprehension, application, synthesis, extended abstract - are exemplified below.

- Comprehension: the comment "the book is about a dog who is lost" would be coded linguistically as description, as the language features include general nouns and action verbs used to recount a summary of the plot. This equates with the comprehension level of Bloom's taxonomy as the student can retell core events in the story accurately.

- Application: the comment "I liked the story about the ducks because it has a good message in the end" would be coded linguistically as personal opinion, as the language features include personal pronouns, thinking verbs and valueloaded adjectives. This equates with the application level of Bloom's taxonomy as the student uses description of an action character to discuss the book at a personal level of meaning.

- Synthesis: The comment "the texture of broken charcoal used by the artist to write the words simulate the effect of the bushfire" would be coded linguistically as emerging critical awareness, as the language features include technical vocabulary and verbs describing the author's actions. This equates with the synthesis level of Bloom's taxonomy as the student is using their knowledge of the text to comment on narrative as created text. 
- Extended abstract: The comment "Since this story is a metaphor about how human refugees find new homes, we think that if anybody was in a detention centre they would want the key to get out, and while the ducks were in the cage it was like they were in a detention centre" would be coded linguistically as critical awareness. This equates with the extended abstract level of Bloom's taxonomy as the student uses meta-linguistic knowledge to demonstrate their grasp of cultural contexts in which stories are created and located.

\section{Results}

How does online collaborative learning support critical thinking? The main aim of this study was to examine how the integration of ICT in a teacher-guided COLC could support students' critical thinking. As linguistic analysis makes clear the difference between levels of understanding, the method enabled an objective view of classroom data to be created for evidence of the following:

(1) Students' initial critical awareness measured through use of meta-language in face-to-face classroom work.

(2) Students' developing critical awareness measured through increased use of meta-language with blended face-to-face and online interaction.

These results are presented below as two stages of findings for focus students chosen to represent key patterns of change over time.

\section{Benchmarking initial critical awareness}

To set up an initial measure of the level of critical awareness students had at the beginning of the rap, data were collected from their first rap point task. In the first rap point, students were asked to respond to the meta-linguistic term token. To carry out the first task successfully, the students needed not only to comprehend the term but also to apply it in their discussion to prepare the subsequent posting. Comprehension of the term token was therefore used as the base benchmark achievement when the first rap point postings were made online. Data were collected from the three IWP focus students as well as the most complex response from a Different School (DS) posting. The benchmarking figure below of Focus Student 1 (FS1), Focus Student 2 (FS2), Focus Student 3 (FS3) and Different School 1 (DS1) demonstrates the different understanding each student had of the concept of token. ${ }^{3}$ FS1 shows the lowest level of critical awareness (comprehension) and DS1 the highest level of critical awareness (extended abstract thinking).

extended abstract
synthesis
application
comprehension

\begin{tabular}{|c|c|c|c|}
\hline & & DS1: Key \\
\hline & & FS3: Map & \\
\hline & FS2: Frog & & \\
\hline FS1:Tree & & & \\
\hline
\end{tabular}

Figure 1. Taxonomy for benchmarking levels of critical awareness. 
The benchmark measure of literacy outcomes at the beginning of the rap positioned the focus students as in Figure 1.

This following section of the paper describes the learning experiences that supported students' progress towards critical awareness. For rap point one, all students were asked to consider the 'journey' that characters experienced in each of the books and to represent it as a 'token'. The rappers at IWP painted rocks to represent this journey, and sent an image to the rap list gallery in response to this task. Prior to painting their rocks, the students had worked as a whole class discussing what a token might be. Then the students moved into their small groups where they discussed their concept of what token would suit their particular book best. The video data caught focus FS1 verbalising her thoughts about the meaning of this term:

A token is, is sort of like a picture, it can be anything sort of but in this, in this part now, it's a picture that sort of describes the whole, like the whole book ...

This child verbalises her thinking about the new concept with her group. It is important to note that this group had been named as the least able of the six groups. Yet even at this early stage these students were not only noticing more details in the text but were also driven to justify personal opinion. At the end of their discussion, the group had two opposing views about their choice of token. Therefore, each student had to defend their individual decision in order to reach consensus. As a result of the discussion work, FS1 wrote in her journal:

I chose a tree from Belongings because throughout the book, it sort of, the environment changes to a more natural environment with trees and stuff.

Although accurate, this is a simple description of what happens in the book. FS1 does not use meta-language to support her view, and nor does she reword the term token to clearly show her understanding.

By comparison, FS2 clearly demonstrates the application of reasoning building towards critical thinking in his comment on the token he painted:

My token is the frog from the swamp. When the swamp was destroyed the frog had to hop away to find a new swamp so the frog was a refugee like the ducks ... Younger children would probably think that the frog was just for decoration and would not know that the frog was also a refugee because his home and the ducks' were destroyed together.

The student names his image a token but does not reinterpret the meta-linguistic term to demonstrate his understanding. Although he uses illustrative terminology, he is caught up in describing the theme of the story and not the symbolic reasoning behind his token. This is the benchmark level comprehension plus application of the term token.

FS3 demonstrates construction of opinion as well as critical reasoning and is also able to reinterpret the meta-linguistic term token by rewording it using her own expression. She speaks of how her token of a map represents a symbolic meaning related to the setting of the book.

The token I painted is a map of Australia. It represents the map that the family's grandparents hung on their wall to trace the family's journey. The brown colour I painted it, represents the dryness of Australia. 
This student represents the benchmark levels comprehension, application and synthesis of the term token from Figure 1.

\section{Developing levels of critical awareness in text response}

This section of the paper reports on the analysis of data from phase three of the project. All the rap postings were available so that changes across time could be measured. The discussion of rap point one showed how the focus students were at different levels of critical awareness at the beginning of the rap. In rap point two, students were encouraged to consider illustrators' deliberate use of visual techniques. The connection between technique and effect needed to be explored before students could address this rap point with knowledge. The teachers provided explicit scaffolding about image through 'talking out' the image (Simpson 2005). The teachers discussed with the students how the illustrators strategically used visual techniques and particular artistic media to affect readers. There is evidence of some progress in critical awareness highlighted in the example of the focus student below.

FS2's response is one of many that demonstrate how students thought critically about the illustrations after the intervention by the moderator and the teacher. The student has comprehended the concept of strategic choice of technique, applied the concept to a particular image, synthesised its use in another context and given critical comment on the effect. This is a stage higher in the taxonomy than their prior response demonstrated at rap point one.

On page 11-12 the background is dark and there is a full moon that outlines the ducks resting on the pipes ... The darkness represents sadness, loneliness and homesickness ... This effect catches the eye. Lighting has an effect on the mood. Like if a setting is dark and kind of scary you wouldn't expect kittens having a party would you? Instead you'd expect a monster stalking kids.

Rap point three asked the students to identify a local social issue that appears in a picture book and to discuss their perception of how their community relates to this issue. Working within a COLC with participants from across Australia, the range of localities and issues was broad. Yet the rap point encourages students to focus on perceptions of their own context. The IWP students' responses in this rap point demonstrate a shift from critical analysis of text construction to include reflections on emotional responses. Again there is evidence of some progress towards critical awareness highlighted in the example of the focus student below.

FS2's response demonstrates strong critical awareness of the link between fiction and reality.

Our issue for Refugees is in the first few pages. It's when the ducks lose their home. It makes you feel sad. When ducks lose their home they become Refugees ... There are Refugees all over the world. In wars and invasions millions of people lose their homes. Australia gave donations to the refugees when the Tsunami hit Asia.

The student's level of critical awareness is high but not much higher in terms of literacy achievement than his benchmarked example.

By phase four, FS1 - the student who had struggled to work out her personal understanding of what the term token meant - had become very aware of visual 
techniques. She now recognises the relationship between technique, strategic choice of design and meaning and critical viewing of image:

The things I have learnt over the past few weeks is not looking at a page and just turning it over again and again. It is looking at the medium and seeing what the camera angle is.

Compared with her initial benchmark, this student shows signs of improvement. She commenced operation at level one of the taxonomy, comprehension. After working in the book rap project, she is beginning to be aware of her own learning and therefore is heading towards a higher level of critical reflection through application and synthesis of knowledge.

From these examples it can be seen that engagement in the book rap encouraged critical thinking for the focus students. After the detailed analysis of the focus samples, when the researcher read across the body of the data for comparison, it appeared that the changes the focus students made represented cluster points for the rest of the data. That is, those who began at the mid-range levels of achievement moved laterally to develop deeper appreciation of social issues. Those who began at the lower level made gains in critical literacy outcomes. This achievement does not guarantee that they will continue to operate at this level, but it does suggest that the book rap was a rich, collaborative learning experience that could support students across a range of abilities in the community.

\section{Teacher attitude to the integration of ICT}

This section of the paper reflects on the role of the teachers in the integration of ICT in the literacy programme and subsequent improvements in students' critical awareness. For example, the teachers at IWP organised access to emails such as the one quoted below sent to the rap list from a different school (DS1).

Our memento for the book 'Refugees' is a key, to symbolise when they were released from the cage into a new swamp. It represents freedom because they were imprisoned in the cage and also metaphorically the key was used to unlock them from their un-welcoming journey.

The student who wrote this email incorporated into it construction of critical reasoning as well as meta-linguistic awareness. The opportunity for all members of the COLC to read this sophisticated posting is an example of how the integration of ICT provided opportunities for knowledge sharing. The advanced level of critical thinking could be used by learners from other schools as a stimulus for new knowledge construction depending on the teacher's presence in the discussion (Anderson et al. $2001,9)$. In the case of IWP, the classroom teacher actively facilitated discourse about different readings of the same book based on this posting. The reinvigorated discussion supported by teacher intervention highlights the importance of the teacher presence in this blended learning context. However, in this instance it was not the moderator of the email list who provided direct instruction to the IWP students. In the IWP context, the responsibility of teacher presence is shared between the online teacher and the in-class teacher. The combined elements of rap design, rap facilitation and direct instruction were co-presented across the synchronous and asynchronous interactions. 
Reflecting on their experience integrating ICT with literacy, the teachers at IWP had a 'big picture' view of what they had tried to achieve. They commented on the change in their expectations in their final interview:

It wasn't about emailing in the end. Where initially we thought it was going to be ... it wasn't really [about working online], because the logistics just don't work that way in schools.

This and other candid comments contained operational, cultural and critical information. It is clear that there were logistical issues with the integration of ICT yet the teachers were comfortable with how the technology fitted into their programmes. They were pleased with the outcomes for the students. In terms of Schibeci et al.'s framework, the description of how they initially set up the classroom ICT culture could be judged at stage two of the framework, Black Line mastery (Schibeci et al. 2008, 318). This level is judged from their uncritical acceptance of the rap point activities and downloadable activity sheets. However, as the rap developed, the teachers became more alert to the learning potential for individual students and, despite the limit of access, became more confident with the COLC. The saw that the book rap provided "a series of learning activities that encourage[d] independent study and community building, that deeply explore[d] content knowledge ... and respond[ed] to common and unique student needs" as an example of effective online learning (Anderson and Elloumi 2004, 276). Teacher attitudes shifted towards Schibeci et al.'s stage three: routine student use. This level can be judged by the teachers' hand-over of responsibility to students to work directly online without intervention. The change in their behaviour showed they had become more critically aware of the impact of this COLC on student learning (Schibeci et al. 2008, 320).

\section{Discussion}

In most COLCs a moderator plays a large role (Salmon 2000). By contrast, in the particular COLC of book raps, which is designed to operate in blended learning classroom contexts, the role of the online moderator is marginalised as students work collaboratively in groups in the school classroom as well as participate in the online context under the guidance of their teacher. Input from the online moderator is provided in the form of instructions for actions as well as content for learning, but this information is largely for the teachers' use. In the book rap context it is the classroom teacher who more frequently intervenes to model, instruct and scaffold student learning in the face-to-face context. Although the online moderator communicates via the COLC in a many-to-many relationship (Warschauer 1997, 470), the asynchronous online teaching presence is far less dynamic than the real-time classroom teacher. In essence, the classroom teacher acts as the facilitator to the moderators' pedagogic design. In terms of interaction, the student experience occurs in a split-level context, which operates internally within their own class and externally connecting to others via the Internet. Members of the COLC of learners communicate briefly and at a distance via a moderator. It is only when the products of the classroom discussion are posted online and communicated with others that the connection between the learners is made. The engagement with this larger community of learners adds an essential layer to the individual student's learning allowing them to experience different ideas 
and responses to literary texts from peers located in another time and place (Anderson and Elloumi 2004).

In summary, the raps are successful in setting up learning conditions to support text response through the choice of books, rap points, tasks, and rap sheets. Students learn by working with others, and the inclusion of online interaction through email encourages a broader range of possible learning scenarios. However, it is clear from the pattern of online interactions that students did not need to learn much about technology in order to take part in the rap. The lack of direct technological involvement for students is highlighted in the final rap wrap-up email. The students wrote the following message to the moderator in response to the stimulus rap point asking them what they had learned through participating in a rap. The students replied:

Our whole class discussed what we had learnt from participating in the book rap. These are our ideas. We liked finding out about different schools and where they are in Australia. Often different schools had different ideas to us. We cooperated in our groups with people we didn't normally with. We found out information on sending email e.g. put a subject. All the books had a journey involved and an issue in our society so we learnt about these issues. We also learnt that the author used words and positions and to make the text interesting. When looking at books there is a lot more than just the writing to think about. You need to study the pages carefully to look at the illustrators' techniques because they add extra meaning.

The final rap point that reports the impact of their work with technology can be classified into four themes: first raps supported students to communicate with students in other learning contexts to broaden their perspectives; second raps helped them learn email etiquette (e.g. 'put a subject'); third raps encouraged them to relate books to their own lives; and fourth raps taught students how to read critically and appreciate texts as created artefact. This posting suggests that the raps met both technology and literacy outcomes. However, the data show that the greater balance of learning took place in the literacy focus whereas only minimal evidence of technology learning was found.

One reading of this situation in the case of IWP could be that although the email lists existed and the students' emails were published online and archived, the students were given little to do with this process while teachers became confident with how the raps operated. Initially teachers took responsibility for reading (and vetting) the incoming emails and posting the outgoing emails as mediators. At the start of the rap, the students wrote their replies up as Word documents and did not deal directly with the 'live' email context. This pattern altered as teachers became more confident in the process and realised they could put students in charge of some processes as students were familiar with logging on and using email programmes.

The teachers' critique of the rap design in their reflective interviews supports this reading. They commented that there were two different technology angles to the book rap: one connected students with books through networked learning, and the other required email exchanges. It was the teachers' opinion that to achieve literacy outcomes the students needed to be actively involved in the reading of and responding to literary texts but the need for each student to be directly involved with online communication was low. Therefore, they could see how book raps would bring about improvements in critical literacy but they could not see how the rap design demanded that students use any new technologies. In Salmon's terms these students were learning frustrated not learning facilitated (Salmon 2000). 
Since the data from this study were collected, book rap designers have recognised the importance of creating more open collaborative opportunities and now incorporate Web2.0 technologies in current raps to encourage students to share a wider range of interactive, multimodal texts rather than just emails. In response to changing technologies, and perhaps influenced by research on the importance of dynamic learning in COLC, the DET book rap site now lists blogs, wikis, digital stories, videos and other options as means for students to communicate with each other about the books they read. The changes to the website clearly support teachers' interest in building technology into primary school classrooms whilst further cementing links to literacy outcomes. Because students will need to create multimodal texts in order to take part in these new activities, teachers will be challenged to build multi-literate pedagogies into their lessons (Simpson and Walsh in press ). Further study of the affordances these new technologies provide to learners in the book raps is now needed to investigate improvements in the use of COLC.

\section{Conclusions}

The importance of this study is the contribution it makes to the field of computing and education using linguistic analysis to pinpoint the achievements made through the integration of technology and literacy. The findings show that the book rap successfully created a network that delivered stimulus material to which teachers and students formed various responses both online and offline. The book rap context is a well-functioning model where technology can be used to encourage response to texts through collaborative learning, both through face-to-face and online communication.

There is great potential for collaboration in COLC such as book raps but students in the IWP research study needed access to more interactive technologies more often for them to be active members of the online community. Teachers could have designed ways of using the site to support greater independence with technology to scaffold collaborative learning, but in their first experience of integrating technology into their literacy programme they did not. It is clear from the discussion above that in terms of educational outcomes, although there were gains in critical thinking, there was little student engagement with technology. The designs for this particular COLC in its blended learning environment needed more work in order to encourage students to take a stronger part in dynamic collaborations to meet strategic goals for literacy and technology. Fortunately, the current book rap site shows that these changes are already taking place.

\section{Notes}

1. See Raps and Book Raps. http://www.schools.nsw.edu.au/raps/index.htm.

2. See Children's Book Council Awards. http://www.cbc.org.au.

3. A token is a physical representation of a symbolic meaning - the visual equivalent would be icon. The term 'token' is used in the online rap sheets.

\section{References}

Anderson, T. and F. Elloumi, eds. 2004. Theory and practice of online learning. Athabasca, Canada: Athabasca University.

Anderson, T., L. Rourke, D. Garrison, and W. Archer. 2001. Assessing teacher presence in a computer conferencing context. Journal of Asynchronous Learning Networks 5, no. 2: 1-17. 
Bell, F. 2009. The agency of students, teachers and learning technologists. ALT-J, Research in Learning Technology 17, no. 2: 73-4.

Bloom, B.S., M.D. Englehart, E.J. Furst, W.H. Hill, and D.R. Krathwohl. 1956. Taxonomy of educational objectives. Handbook 1: Cognitive domain. New York: Longmans, Green.

Christie, F. 2002. Classroom discourse analysis: A functional perspective. London: Continuum.

Department of Education Science and Training. 2001. Making better connections: Models of teacher professional development for the integration of information and communication technology into classroom practice. Canberra: Commonwealth Department of Education, Science and Training.

Dillenbourg, P., and D. Traum. 2006. Sharing solutions: Persistence and grounding in multimodal collaborative problem solving. Journal of the Learning Sciences 15, no. 1: 121-51.

Downing, K.J., T. Lam, T. Kwong, W. Downing, and S. Chan. 2007. Creating interaction in online learning: A case study. ALT-J, Research in Learning Technology 15, no. 3: 201-15.

Durrant, C., and B. Green. 2000. Literacy and the new technologies in school education: Meeting the L(IT)eracy challenge? Australian Journal of Language and Literacy 23, no. 2: 89-108.

Ellis, R., P. Goodyear, A. O'Hara, and M. Prosser. 2007. The university student experience of face-to-face and online discussions: Coherence, reflection and meaning. ALT-J, Research in Learning Technology 15, no. 1: 83-97.

Halliday, M. 1975. Learning how to mean: Explorations in the development of language. London: Edward Arnold.

Lankshear, C., C. Bigum, C. Durrant, B. Green, E. Honan, J. Murray, W. Morgan, I. Snyder, and M. Wild. 1997. Digital rhetorics: Literacies and technologies in education - Current practices and future directions. Canberra: DEETYA.

Martin, J.R. 2000. Close reading: Functional linguistics as a tool for critical discourse analysis. In Researching language in schools and communities: A functional linguistic perspective, ed. L. Unsworth, 275-303. London: Cassell.

Owen, M. 2004. Just a tool? The computer as the curriculum. In ICT for curriculum enhancement, ed. M. Monteith, 26-40. Bristol: Intellect.

Salmon, G. 2000. Emoderating: The key to teaching and learning online. London: Kogan Page.

Schibeci, R., J. MacCallum, W. Cumming-Potvin, C. Durrant, B. Kissane, and E. Miller. 2008. Teachers' journeys towards critical use of ICT. Learning, Media and Technology 33, no. 4: 313-27.

Simpson, A. 2005. Four roles for the viewer? Developing an understanding of visual literacy. Paper presented at the Pleasure, Passion and Provocation: AATE/ALEA National Conference, July, in Gold Coast, Australia.

Simpson, A., and M. Ollila. 2004. Dimensions of design: A comparison of professional development in two online learning communities. Paper presented at the 4th IEEE International Conference on Advanced Learning Technologies, August 30-September 1, in Joenssu, Finland.

Simpson, A., and M. Walsh. In press. Multiple literacies: Implications for changed pedagogy. In Literacy and social responsibility, ed. F. Christie and A. Simpson. London: Equinox.

Stubbs, J. 1999. Book raps: An Internet project. In The Net effect, ed. L. Hay and J. Henri, 58-63. London: The Scarecrow Press.

Turvey, K. 2006. Towards deeper learning through creativity within online communities in primary education. Computers and Education 46, no. 3: 309-21.

Unsworth, L., ed. 2000. Researching language in schools and communities: A functional linguistic perspective. London: Cassell.

Unsworth, L., A. Thomas, A. Simpson, and J. Asha. 2005. Children's literature and computerbased teaching: From book raps to story palaces. Buckingham: Open University Press.

Warschauer, M. 1997. Computer-mediated collaborative learning: Theory and practice. The Modern Language Journal 81, no. 4: 470-81.

Webb, M.E., and M. Cox. 2004. A review of pedagogy related to information and communications technology. Technology, Pedagogy and Education 13, no. 3: 235-86. 